\title{
Cloud Forms.
}

THE United States Weather Bureau at Washington has issued a publication ${ }^{1}$ which would seem to be intended as a guide to cloud forms for meteorological observers. It consists of a short introduction, two diagrams of cloud height frequencies, a page devoted to definitions of cloud forms, taken from the International Cloud Atlas, and 32 photographs of different forms of cloud. The memoir gives in convenient form information which will be useful to meteorological observers, and if any criticism may be made, it is that a few of the photographs are not quite typical and some are not clear.

All modern cloud classification is based on the International Cloud Atlas. The classification adopted there is based on appearance. It is also recognised that form has been found to be largely dependent on height, and American observers argue that "it is therefore possible to gain information concerning the direction and velocity of the wind aloft by assigning the cloud to the height of most frequent occurrence, even though its exact height at the particular time is not known." This method has been widely used, but it has always seemed to the writer to be a procedure of very doubtful validity, especially when applied, as it frequently has been, to cirrus, for although, as we learn from the Weather Bureau Memoir, "the height of maximum frequency both summer and winter was between 8000 and 8400 metres," out of 227 measurements, yet there was a secondary maximum some 2000 metres higher. "Seven-tenths of all cirrus observed were found between 7600 and I I, 200 metres," which is a fairly wide range, while cirrus has apparently been observed at Blue Hill, Mass., so low as 2400 metres and so high as I5,000 metres.

The method of assuming cloud heights and deducing the wind velocity at the cloud level by observing the drift is therefore liable to grave errors; the one theodolite method of observing pilot balloons has been much criticised on the same grounds, but on days when convection currents are not very active, it is not so liable to error as the cloud method. One can never be certain without cloud height measurements that one is dealing with a cloud at an average height.

The consideration of the maximum height of cirrus brings to mind the so-called " night shining clouds" observed in the last two decades of the nineteenth century, supposed to be associated with the eruption of Krakatoa. They had all the appearance of cirro cumulus, but their height was about 50 kilometres. The highest cirrus measured by $\mathrm{A}$. W. Clayden was $27 \frac{1}{2}$ kilometres; there is thus a region of more than 20 kilometres in which clouds have never been observed, and then a level where they have been observed on rare occasions. Perhaps it is more than a coincidence that the height of the night shining clouds corresponds with the secondary or lower maximum of meteor disappearance as determined by Lindemann.

The two diagrams reproduced here (Figs. I and 2) give cloud height frequencies for the various forms of cloud, for summer and winter respectively, as observed at Blue Hill, Mass., based upon tabulations for each 400 metres, by H. H. Clayton. These diagrams are extremely interesting, and we wish that similar diagrams could be constructed for other parts of the globe ; there must be a considerable body of informa-

1 U.S. Department of Agriculture, Weather Bureau, "Cloud Forms according to the International System of Classification." Prepared by the Cloud Committee: Benjamin C. Kadel, Harry C. Frankenfield, and Franklin G. Tingley. Pp. 22, (Washington: Govern
ment Printing Office, n.d.) n.p.

$$
\text { NO. } 2879 \text {, VOL. I I } 5 \text { ] }
$$

tion which might be made available, for there are to-day more methods than formerly of determining cloud heights. The diagrams show very clearly over what a wide range of height the various cloud forms

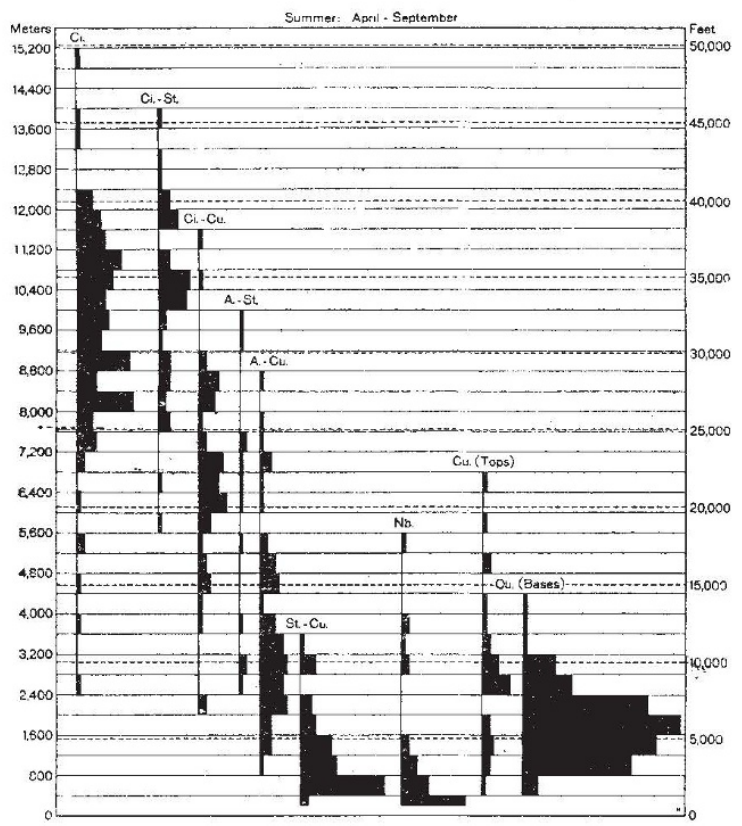

Frg. I.-Cloud height frequencies, April to September, I890-9I and r 86 -97, Blue Hill, Mass., based upon tabulation for each 400 metres, by $\mathrm{H}$. H. Clayton. Relative frequency is indicated by width of figure. From "Cloud Firms."

extend; alto cumulus overlaps cirro cumulus, and strato cumulus overlaps alto cumulus, and one is tempted to wonder whether there is any essential difference between the three forms, since neither in

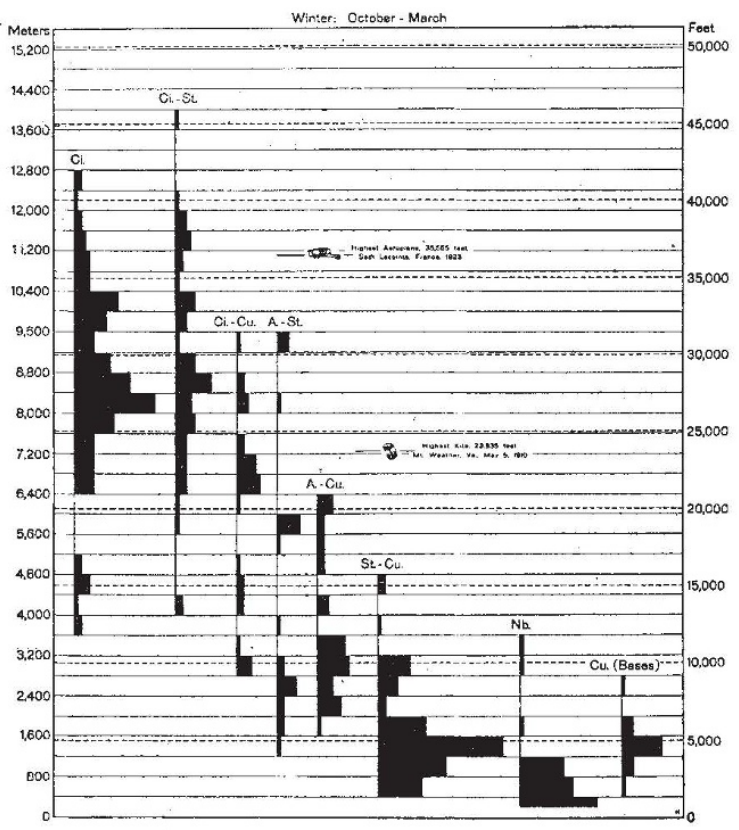

Fig. 2.-Cloud height frequencies, October to March, I8go-9I and $1896-97$, Blue Hill, Mass., based upon tabulation for each 400 metres, by H. H. Clayton. Relative frequency is indicated by width of figure. From "Cloud Forms." 
appearance nor in height is there any line of demarcation. This is indeed recognised, for in one of the photographs, illustrating the Weather Bureau publication, of strato cumulus or alto cumulus, a note is added that " these same clouds would be called strato cumulus by an observer nearer to them and alto cumulus by an observer farther from them (as at sea level)." The heights given for nimbus are curious; the maximum frequency is quite low, 400 metres for both summer and winter, but there are occasional observations at higher levels, one in summer so high as 5000 metres.

The photographs which constitute the bulk of the
Weather Bureau Memoir are interesting; and some, such as the undulated alto stratus seen from above at Mount Wilson (Plate II), and the same form of cloud seen from below at Washington (Plate $x_{3}$ ), are very beautiful. There is one remark to which exception might be taken; it occurs as a note under a fine photograph, by Sir David Wilson-Barker, of small alto cumulus, and runs: "Even if there are no shadows the presence of coronas or iridescent colours near the sun or moon distinguish such small alto cumulus from cirro cumulus." In the present writer's experience, iridescence and coronæ are quite common in clouds which would be classified as cirro cumulus.

\section{The Locust Problem and its International Solution. ${ }^{1}$}

\section{By Dr. A. D. Imms.}

$\mathrm{IT}^{\mathrm{T}}$ is a matter of common knowledge that the damage occasioned by locust invasions is frequently extremely serious. Thus, in the year I874, the destruction brought about by these insects in the Rocky Mountains amounted to approximately forty million dollars. In Igo8 an estimated damage of one million sterling was caused by locusts to crops in the Transvaal, while the cotton crop in Egypt has often suffered severely. The intensity of an attack, and some idea of the damage done, may be gauged from the number of locusts often found within a comparatively small area. For example, in Southern France in 1920 , between twelve and thirty million locusts were destroyed daily, while twenty tons of eggs were collected in a single month in the Argentine in March I9I5. Since the year I9I4 the countries affected by locusts include the greater part of Africa, certain parts of Spain, France, Italy, Asia Minor, Turkestan, etc. The regions more especially affected lie between $20^{\circ}$ and $40^{\circ}$ latitude north and $15^{\circ}$ and $45^{\circ}$ latitude south, the equator being comparatively immune. In order to deal with these outbreaks some international organisation appears necessary, and it is to be hoped that the League of Nations will lend its authority to assist in arriving at a concerted plan of action. The need for international action is obvious when it is remembered that locust swarms can travel 18 to 300 miles in a single day, thus easily migrating from one country into another.

Very large amounts of money are spent yearly by some countries on preventive measures. The danger to public health caused by locust invasion is far smaller than formerly, and the last severe famine due to locust devastation was in I866. In that year about 200,000 natives perished in North Africa. The obstruction and poisoning of wells and other water supplies, however, may still entail very serious consequences.

No really adequate biological studies of locusts are available, and knowledge has scarcely yet progressed beyond empirical methods. Much that has been written on the migration and breeding of these insects is sufficiently untrustworthy to demand renewed investigation. Important work, however, has been done by Uvarov, J. C. Faure and Hernandez. Among the results achieved, the most important is the demonstration that certain species of locusts have two distinct phases in their development: the migrating or gregarious phase and the solitary or individual phase. Uvarov has devoted attention to the problem of migrations. These are not the result, as commonly supposed, of the necessity of finding fresh food. Locust swarms frequently leave fertile lands for others which are far less so. The factors governing these

1 "Le problème acridien et sa solution internationale." By Paul Vayssière, in Matériaux pour l'étude des calamites, No. 2, 1924, pp. 122-158. (Publiés par les soins de la Société de Géographie de Genève.) migrations need renewed study, but they appear to be governed by variations of temperature rather than by the availability of vegetation. Important changes in the physiology of the individual locusts have also been observed during migration. Until sufficient biological data are available, emergency action will have to be continued in order to restrict migration and the resulting damage to crops. It is to be hoped, however, that the problem will be solved if the States interested will provide for the biological investigation of locusts instead of being satisfied with occasional emergency measures.

Methods of control are very varied, and it may be added that the utilisation of natural agents has been insufficiently explored. The study of the insects' parasites demands further attention, and we are still not in a position to say whether important results may or may not be expected from this line of work. Attempts at propagating bacterial or other diseases have not yet been successful. Mechanical methods by means of artificial barriers are numerous, and these provide the means for arresting and destroying locusts in bulk but they are not by any means adequate. Physical methods - the use of fire-have been applied in various ways. The modern French method of using the army flame-projector has been employed with great success in Algeria. A single charge of I2 litres of crude oil is sufficient to destroy all locusts gathered on a surface of 500 square metres. Among chemical methods, the use of poison gas has not proved successful in experiments. Among insecticides, arsenate of soda appears to be the most satisfactory compound, and in Italy other methods of destruction have now been abandoned.

International conventions for combating these insects first came into being in South America and South Africa. A further important step was taken at the Rome conference of I920, when thirty-five countries signed a convention naming the International Agricultural Institute as the headquarters of an International Locust Information Bureau. Unfortunately, it does not seem that much progress has been made, and the International Institute has not been in a position to publish reports from the Governments concerned except a few from Algeria, Bulgaria, French West Africa, and Hungary. Good work, however, has been done by North African countries, which have concluded a special agreement among themselves. It is to be hoped that effect will be given to the resolutions of the I920 Convention and that the need of financing skilled biological study of locusts will be recognised. M. Vayssière outlines a scheme of the international organisation he proposes and suggests the League of Nations as being best able to give that assistance necessary to secure effective international co-operation of the kind required.

$$
\text { NO. } 2879 \text {, VOL. I I } 5 \text { ] }
$$

